\title{
The Evaluative Consequences of Hedges, Hesitations, and Intensifiers Powerful and Powerless Speech Styles
}

\author{
LAWRENCE A. HOSMAN \\ University of Southern Mississippi
}

\begin{abstract}
This article examines the separate and combined impact of hedges, hesitations, and intensifiers on perceptions of authoritativeness, sociability, character, and similarity, and the extent to which messages containing one or more of these language variables differs from a "prototypically" powerless message in evaluative consequences. A "prototypically" powerless message is one that contains not only hedges, hesitations, and intensifiers, but also contains polite forms and meaningless particles, such as "oh, well" and "you know." Two studies indicated that hedges and hesitations individually affected perceptions of authoritativeness and sociability, but interactions among the variables were not found in the studies. Furthermore, only high intensifiers/low hedges/low hesitations and low intensifiers/low hedges/low hesitations messages differed significantly from the "prototypically" powerless message. The second study revealed that speaker status interacted to affect evaluative consequences. The results are discussed in terms of their implications for the power of speech style construct.
\end{abstract}

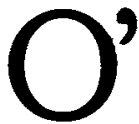

Barr and associates (1978) introduced the concepts of "powerful" and "powerless" speech styles in an inspection of court transcripts that revealed that a powerless speech style, one used by those low in ascribed power, was characterized by numerous language features, including hedges ("sort of," "kind of"), intensifiers ("really," "very"), hesitations ("um," "er"), polite forms, and deictic phrases ("over there"). A powerful speech style did not exhibit these features. From their observations they constructed experimental tapes reflecting these differences and asked subjects to evaluate the

Lawrence A. Hosman (Ph.D., University of lowa, 1978) is an associate professor in the Department of Speech Communication at the University of Southern Mississippi. Thanks is given to Keith Erickson and Susan Siltanen for helpful comments on an earlier version of this article. The first study was presented at the annual meeting of the Speech Communication Association, Boston, MA, November 1987.

Human Communication Research, Vol. 15 No. 3, Spring 1989 383-406

- 1989 International Communication Association 
competence and attractiveness of the speakers. They found that powerless speech was perceived as less competent and less attractive than its powerful counterpart.

Studies of the evaluative consequences of powerful and powerless speech styles (Bradac, Hemphill, \& Tardy, 1981; Lind \& O'Barr, 1979; Warfel, 1984) have consistently found that powerful speech is perceived as more competent than powerless speech. More contradictory results have been obtained for judgments of attractiveness. Bradac et al. (1981, Study 1) and Warfel (1984) found that powerful speech was perceived as attractive; another study (Bradac et al., 1981, Study 2) did not.

Several studies focused on the components of the power of speech style construct, their rationale being twofold. First, it is difficult to determine whether the language features constituting the powerful/ powerless speech style constructs equally indicate power. One or two variables may have major evaluative consequences, while other variables may have negligible evaluative consequences.

Second, even if all of the features contribute to the evaluations, researchers cannot determine whether the contributions are equal, additive, or contradictory. For example, intensifiers may increase the force of a statement, while hedges reduce it. Although both are present in powerless speech, it is unclear how they combine to affect perceptions of competence or attractiveness. Accordingly, this article reports the results of two studies that examine the evaluative consequences of three powerless/powerful speech style componentsintensifiers, hedges, and hesitations.

\section{POWER OF SPEECH STYLE COMPONENTS}

Researchers have systematically assessed the evaluative consequences of power of speech style components. Bradac and Mulac (1984) examined individual components finding a hierarchy of power. Some language features were perceived as relatively powerless (tag questions and hesitations), while others were perceived as relatively powerful (polite language and intensifiers). This hierarchy was stable whether a speaker's intention was to be sociable or authoritative. Bradac and Mulac did not, however, examine any interactive effects between the components.

Wright and Hosman (1983) examined the interactive effects of hedges and intensifiers, finding that hedges influenced perceptions of credibility and attractiveness, but intensifiers did not. Hosman and 
Wright (1987) found that hedges and hesitations interacted to affect perceptions of authoritativeness and attractiveness. Contrary to O'Barr's conceptualization, the presence of both hedges and hesitations did not produce the most negative evaluations of authoritativeness or the most negative perceptions of attractiveness. Thus powerful/ powerless speech style components may interact in novel ways to affect evaluative consequences.

The studies reported here examine the effects, both individually and in combination, of three components of speech-hedges, hesitations, and intensifiers. These components were selected for four reasons. First, these components occurred with the greatest frequency in O'Barr's original data and ought to have the greatest impact on evaluative consequences. Second, Bradac and Mulac (1984) found that the features not only represented different points along the power continuum, but they also differed significantly from one another in perceived power. Third, numerous studies have found that hedges, hesitations, and intensifiers individually have important evaluative consequences. For example, several studies (McCroskey \& Mehrley, 1969; Miller \& Hewgill, 1964; Sereno \& Hawkins, 1967) reported that hesitations are negatively related to perceptions of competence, dynamism, and character. Other studies (Bradac \& Mulac, 1984; Newcombe \& Arnkoff, 1979) indicated that intensifiers are perceived as relatively powerful.

There are at least four plausible explanations for how these components interact. One explanation (O'Barr, 1982) holds that these components are each indicative of powerlessness, and, when combined, produce an additive effect such that all three will be perceived as very powerless. Another explanation (Bradac \& Mulac, 1984) suggests that although the three may represent different points along a power continuum, they may uniquely combine to produce a coherent picture of powerlessness, but one that is not predictable from knowledge about the individual components. This would be a nonadditive or "whole-isgreater-than-the-sum-of-its-parts" effect. A third account holds that the three indicate different levels of power and combine in a message to produce a muddled or confusing picture. Under this explanation previous differences between powerful and powerless styles do not so much represent differences in perceived power as they represent the difference between a coherent message and a confused message. A fourth explanation is that under some circumstances the components could signal powerfulness rather than powerlessness. Hedges are 
related to authoritativeness (Goss \& Williams, 1973), and intensifiers are perceived as powerful (Bradac, Schneider, Hemphill, \& Tardy, 1980; McEwen \& Greenberg, 1970). The various explanations need to be unraveled.

A second purpose is to examine whether messages with combinations of the three components produce evaluative consequences that differ from those produced by a prototypically "powerless" message. A prototypically "powerless" message is one that contains all of the language variables used by O'Barr (1982). Such a message would include hedges, hesitations, and intensifiers, as well as polite forms, use of "sir," and meaningless particles, such as "oh, well." This question asks whether messages containing combinations of hedges, hesitations, and intensifiers produce evaluative consequences similar to those of the prototypically "powerless" message.

This is an important question as researchers argue (Bradac et al., 1981; Hosman \& Wright, 1987) that the "power-of-speech-style" construct is not parsimonious. A powerless speech style may contain elements that make little contribution to perceptions of powerlessness. If a prototypically "powerless" message does not produce different evaluative consequences than messages containing fewer components, then it may be possible to conclude that some of O'Barr's original components are unnecessary. This possibility has not been directly examined. For example, Bradac and Mulac (1984) compared individual components to a powerful message and found that all components but one were perceived as less powerful. They did not explore any interactions among the various components.

A third purpose is to examine the relationship between respondent gender and the evaluative consequences associated with hedges, hesitations, and intensifiers. Despite a number of studies examining the relationship between respondent gender and power of speech style (Bradac et al., 1981; Erickson, Lind, Johnson, \& O'Barr, 1978; Warfel, 1984; Wright \& Hosman, 1983) the relationship is unclear. Some studies (Erickson et al., 1978) found a relationship, while others (Bradac \& Mulac, 1984; Hosman \& Wright, 1987) did not.

Based on the preceding rationale, the following research questions were advanced:

(Q1) Do hedges, hesitations, intensifiers, and respondent gender affect or interact to affect perceptions of a speaker's authoritativeness, sociability, and character? 
(Q2) Do messages containing hedges, hesitations, and/or intensifiers produce different evaluative consequences than a prototypically powerless message?

\section{STUDY 1}

Method

Subjects. Respondents were 131 undergraduate volunteers in communication courses at a southern university. They ranged in age from 17 to $53(M=22.11)$, and represented a wide range of academic majors. Respondents were randomly assigned to experimental conditions.

Messages. A defendant's account of an auto accident served as the kernel message and consisted of six written responses to an attorney's questions. It did not contain hedges, hesitations, or intensifiers and served as the low intensifiers/low hedges/low hesitations message condition. The defendant's gender was not identified in order to reduce the likelihood of gender stereotyping by subjects.

Seven additional messages were then constructed, each containing a low or high level of hedges, hesitations, and intensifiers. Hedges were operationalized using words and phrases such as "sometimes," "sort of," and "maybe." Hesitations were operationalized by inserting ellipses (. . .) or filled pauses and ellipses ("er . ..") in the messages. The hesitations were placed in varying positions within the sentences, consistent with Maclay and Osgood's (1959) research on hesitation occurrence. Intensifiers were operationalized using words and phrases such as "very," "definitely," and "really." For each variable the high condition contained twelve to fourteen occurrences, while the low condition contained no occurrences.

A ninth message represented a prototypically powerless speech style message. It was the same kernel message as the other eight, and contained not only hedges, hesitations, and intensifiers, but also included one polite form, four "you knows," and eight "meaningless" particles such as "Oh, well," "let's see," and "now." These additional language features were included in O'Barr's (1982) version of powerless speech. The six components occurred in approximately the same relative proportion as they did in O'Barr's messages.

The following are excerpts ${ }^{1}$ from five of the messages:

(1) Low intensifiers/low hedges/low hesitations: My car needs work. As for my own personal injuries, I still have a problem with pain in my neck. 
(2) Low intensifiers/high hedges/low hesitations: I'm not sure what all needs to be done to my car, but it needs work. As for my own injuries, they're kind of hard to assess right now.

(3) Low intensifiers/low hedges/high hesitations: My car needs work. As for my own personal injuries ... er ... I still have a problem with pain in my neck.

(4) High intensifiers/low hedges/low hesitations: My car sure needs a lot of work. As for my own personal injuries, I still have a problem with pain in my neck.

(5) Prototypically powerless message: Oh well ... I'm not sure, you know, what all needs to be done to my car, but . . . er . . . it sure needs a lot of work. As for my own injuries ... uh ... they're kind of hard to assess right now. I still have some kind of problem . . . ah . . with bad pain in my neck.

Dependent measures. After reading one version of the testimony, subjects evaluated the witness's authoritativeness or power, competence, character, attractiveness, and sociability on twenty-one seven-interval scales. The competence and character scales were selected on the basis of McCroskey's credibility research (McCroskey \& Young, 1981). The attractiveness scales had been used in previous research (Hosman \& Wright, 1987). The authoritativeness and sociability scales were adapted from Bradac and Mulac's (1984) descriptors of these two impressions.

Design and analysis. For all statistical tests alpha was set at .05 . Research question one was examined by a 2 (high versus low hedges) $X$ 2 (high versus low hesitations) $\times 2$ (high versus low intensifiers) $\times 2$ (subject gender) fixed effects analysis of variance. All were betweensubjects factors. The dependent measures were factor analyzed. Factor scores were computed via a regression method and used as the dependent measures in a univariate analysis of variance. Bartlett's test of sphericity indicated that a multivariate analysis was not warranted $\left(\chi^{2}=.50, \mathrm{df}=3, p=.92\right)$. Follow-up tests were conducted using Duncan's multiple-range test.

Research question two was examined by comparing the eight experimental messages to the single powerless speech style message. A one-way univariate analysis of variance was performed on the dependent measures, with the nine message conditions serving as levels of this factor. Follow-up tests were conducted using Duncan's multiple-range test. 


\section{Results}

Using a principal components factor analysis with iterations, a varimax rotation, and a minimum eigenvalue extraction criterion of 1.0 , a three-factor solution was extracted. The first factor represented an authoritativeness dimension, with the following items and their loadings defining the factor: powerful (.58), competent (.58), authoritative (.78), dominant (.82), strong (.78), aggressive (.76), and confident (.73). The second factor was a sociability dimension, containing the following items and their loadings: pleasant (.82), likable (.68), good-natured (.71), and sociable (.74). The third factor represented a character dimension, with the following items and their loadings defining the factor: honest (.83) and trustworthy (.81).

Cronbach's (1951) alpha was computed in order to determine the internal reliability of the three scales. The reliability of the authoritativeness, sociability, and character scales was $.88, .80$, and .79 , respectively.

Initially, the analyses were performed including subject gender as a factor in the design. Since no main or interactive effects involving gender were significant or approached significance, the data were collapsed across this dimension and all subsequent analyses were conducted using only hedges, hesitations, and intensifiers.

Authoritativeness. There was a significant hedges by hesitations interaction $\left(F[1,108]=7.69, p<.001\right.$, eta $\left.^{2}=.07\right)$, as well as significant main effects for hedges $\left(F[1,108]=13.26, p<.0001\right.$, eta $\left.^{2}=.11\right)$ and hesitations $\left(F[1,108]=5.00, p<.03\right.$, eta $\left.{ }^{2}=.04\right)$. The means and standard deviations for the interaction are in Table 1. Follow-up tests revealed that the message containing a low level of hedges and hesitations was perceived as significantly more authoritative than the other three messages, which did not differ significantly from one another.

In addition, a low level of hedges was perceived as more authoritative $(\mathrm{M}=.36)$ than a high level $(\mathrm{M}=-.34)$, and a low level of hesitations was perceived as more authoritative $(M=.23)$ than a high level of hesitations ( $\mathrm{M}=-.23)$.

Sociability. The data revealed a significant triple interaction among intensifiers, hedges, and hesitations $\left(F[1,108]=3.81, p<.05\right.$, eta $\left.{ }^{2}=.03\right)$, which qualified a significant hesitations main effect $(F[1,108]=4.42$, $p<.04$, eta ${ }^{2}=.04$ ). Table 2 presents the means and standard deviations. 
TABLE 1

Authoritativeness Factor Score Means and

Standard Deviations for Hedges $X$ Hesitations

\begin{tabular}{|c|c|c|}
\hline & \multicolumn{2}{|c|}{ Hedges } \\
\hline & Low & High \\
\hline \multicolumn{3}{|c|}{ Hesitations } \\
\hline \multirow[t]{3}{*}{ Low } & $M=.76^{\mathrm{a}}$ & $M=-.37^{b}$ \\
\hline & $S D=1.00$ & $S D=.96$ \\
\hline & $n=33$ & $n=29$ \\
\hline \multirow[t]{3}{*}{ High } & $M=-.14^{b}$ & $M=-.30^{b}$ \\
\hline & $\mathrm{SD}=.92$ & $\mathrm{SD}=.84$ \\
\hline & $n=26$ & $n=28$ \\
\hline
\end{tabular}

NOTE: Means with common superscripts do not differ significantly, $p<.05$. The higher the score, the higher the authoritativeness.

The follow-up tests indicated that the high intensifiers/high hedges/low hesitations and low intensifiers/ high hedges/low hesitations messages were more sociable than the low intensifiers/high hedges/high hesitations message. The main effect showed that a low level of hesitations was more sociable $(M=.19)$ than a high level of hesitations $(\mathrm{M}=-.21)$.

Character. Only a significant hedges main effect $(F[1,108]=4.47, p<$ .04 , eta $^{2}=.04$ ) was found. Messages containing a low level of hedges were perceived as more trustworthy $(\mathrm{M}=.23)$ than messages containing a high level of hedges $(M=-.19)$.

No other effects were statistically significant (power, medium effect size, $=.75$ ).

Comparison with prototypically "powerless" message. The second research question asked whether hedges, hesitations, intensifiers, or combinations of the three produced different evaluative consequences than a prototypically powerless message. A significant main effect was found for message conditions on the authoritativeness scale, $F(8,122)=$ $4.59, p<.0001$, eta $^{2}=.23$. The means for the messages are contained in Table 3.

The follow-up test revealed that two messages differed significantly from the powerless message. Specifically, the high intensifiers/low hedges/low hesitations messages was perceived as significantly more authoritative than the powerless message. The low intensifiers/low 
TABLE 2

Sociability Factor Score Means and Standard Deviations for Intensifiers $X$ Hedges $X$ Hesitations

Low Hedges ${ }^{\text {High }}$

Low Intensifiers

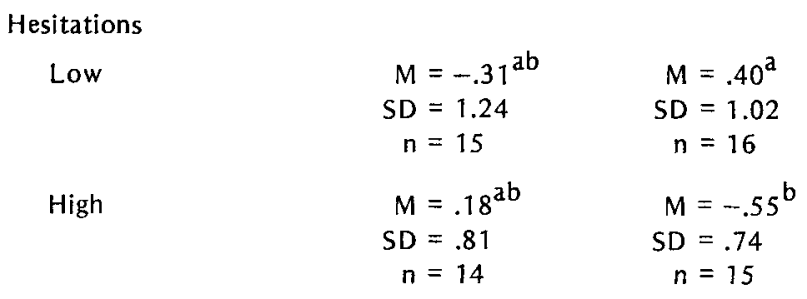

High Intensifiers

Hesitations

Low

$\begin{array}{rlrl}M & =.25^{\mathrm{ab}} & \mathrm{M} & =.43^{\mathrm{a}} \\ \mathrm{SD} & =.91 & \mathrm{SD} & =.65 \\ \mathrm{n} & =18 & \mathrm{n} & =13\end{array}$

High

$$
\begin{array}{rlrl}
M & =-.38^{\mathrm{ab}} & \mathrm{M} & =-.12^{\mathrm{ab}} \\
\mathrm{SD} & =.65 & \mathrm{SD} & =.88 \\
\mathrm{n} & =12 & \mathrm{n} & =13
\end{array}
$$

NOTE: Means with common superscripts do not differ significantly, $p<.05$. The higher the score, the higher the sociability.

hedges/low hesitations message was also perceived as significantly more authoritative than the powerless message. ${ }^{2}$

\section{DISCUSSION}

This study revealed that only hedges and hesitations were related to perceptions of authoritativeness and sociability. In particular, a message without hedges and hesitations was perceived as the most authoritative, while a message high in hedges and low in hesitations was perceived as the most sociable. The second research question asked whether messages containing various combinations of hedges, hesitations, and intensifiers would produce different evaluative consequences than a prototypically powerless message. The low intensifiers/low hedges/low 


\section{TABLE 3}

Authoritativeness Factor Score Means for the Nine Message Groups in Study 1

\begin{tabular}{lc}
\hline & Authoritativeness \\
\hline Low intensifiers/low hedges/low hesitations & $.58^{\mathrm{a}}$ \\
Low intensifiers/low hedges/high hesitations & $-.25^{\mathrm{b}}$ \\
Low intensifiers/high hedges/low hesitations & $-.32^{\mathrm{b}}$ \\
Low intensifiers/high hedges/high hesitations & $-.55^{\mathrm{b}}$ \\
High intensifiers/low hedges/low hesitations & $.92^{\mathrm{a}}$ \\
High intensifiers/low hedges/high hesitations & $-.01^{\mathrm{b}}$ \\
High intensifiers/high hedges/low hesitations & $-.44^{\mathrm{b}}$ \\
High intensifiers/high hedges/high hesitations & $-.02^{\mathrm{b}}$ \\
Powerless message & $-.14^{\mathrm{b}}$ \\
\hline
\end{tabular}

NOTE: Means with common superscripts do not differ significantly from the powerless message, $p<.05$. The higher the score, the higher the authoritativeness.

hesitations message and the high intensifiers/low hedges/low hesitations message were perceived as more authoritative than the powerless message. There were no significant differences between the messages on the sociability and character scales.

\section{STUDY 2}

Although the first study showed that hedges and hesitations produced significant negative evaluative consequences, the results may be limited to content-specific message variables. Thus a second study was conducted. This study had two purposes. The first purpose was to replicate Study 1 using new stimulus materials to assess the generalizability of the message effects (Jackson \& Jacobs, 1983). The second purpose was to extend the first study by investigating the impact of speaker status on the evaluative consequences of hedges, hesitations, intensifiers, and powerless messages, and to examine the impact of these variables on perceived speaker similarity.

Although the evaluative consequences of speaker status have been studied (Bradac, Courtright, Schmidt, \& Davies, 1976; Bradac, Konsky, \& Davies, 1976), they have not been related to powerful and powerless speech styles. Erickson et al. (1978) observed that in a courtroom 
high-status people spoke with a powerful style, while low-status people spoke with a powerless style, a relationship reinvestigated only once. Johnson and Vinson (1987) looked at the relationship between speaker status and power of style, finding that power of style produced more significant effects than speaker status, although speaker status and power of style interacted to affect competence judgments. The relationship between speaker status and the components of powerless speech has not been investigated. One might anticipate, for example, that high-status speakers exhibiting powerless speech style features would receive more negative evaluations than high-status speakers exhibiting powerful features. Low-status speakers exhibiting powerful style components might be evaluated more positively than low-status speakers exhibiting powerless style components. Thus some components may be particularly powerful or powerless depending on the speaker's status.

This study also extended Study 1 by looking at the effect of these speech style components on perceptions of speaker similarity. Berger and Bradac (1982) posited that speaker similarity moderates the relationship between language and uncertainty reduction. Although similarity has been related to other language variables (see Bradac, Bowers, \& Courtright, 1979), it has not been examined in the area of powerful and powerless speech styles. As a first step in trying to provide a theoretical explanation linking power of style to its evaluative consequences, it seemed reasonable to ask whether perceived speaker similarity may be involved.

On the basis of this rationale, the following two research questions guided the second study:

(Q1) Do speaker status, hedges, hesitations, and intensifiers affect or interact to affect judgments of a speaker, including perceived similarity?

(Q2) Do messages containing hedges, hesitations, and/or intensifiers produce different evaluative consequences than a prototypically powerless message?

Method

Subjects. Respondents were 197 undergraduate volunteers (90 males and 107 females) enrolled in communication courses at a southern university. They ranged in age from 17 to $39(M=20.7)$ and represented a wide range of academic majors. Respondents were randomly assigned to experimental conditions. 
Messages. O'Barr's (1982) powerful speech style message served as the kernel message. This message is a witness's description of an accident between an automobile and an ambulance. It was adapted to make it similar in length to the kernel message in Study 1, as well as similar in the total number of witness responses. Since O'Barr's powerful message contained some intensifiers, hedges, and hesitations, they were deleted in order to be consistent with the manipulations used in this study. Once deleted this message constituted the low intensifiers/ low hedges/low hesitations condition.

Seven additional versions of this kernel message were created, each containing a low or high level of intensifiers, hedges, and/or hesitations. Each variable was operationalized and occurred with the same frequency as in Study 1. A ninth version represented a prototypically powerless message, and included the same stylistic components in the same frequency as used in the powerless message of Study 1 . Thus attempts were made to make the nine messages similar to those in Study 1 , with the messages in the two studies differing by content only.

The following are brief excerpts from five of the messages:

(1) Low intensifiers/low hedges/low hesitations: Yes. The ambulance's light was not on, and it did not have a siren.

(2) Low intensifiers/high hedges/low hesitations: Yes. I don't think the ambulance's light was on, and it did not have a siren.

(3) Low intensifiers/low hedges/high hesitations: Yes. The ambulance's light was ah ... not on, and um, it did not have a siren.

(4) High intensifiers/low hedges/low hesitations: I certainly do. The ambulance's light was not on, and it did not have a siren.

(5) Prototypically powerless message: Oh yes, I certainly do. Let's see, I don't think the ambulance's light was ah... on, and um, it did not have a siren.

Procedure and dependent measures. Subjects were given a packet containing an instruction sheet, a message, and evaluative scales. The instruction sheet contained the speaker status manipulation, which was similar to one used by Bradac, Courtright, Schmidt, and Davies (1976). The high-status manipulation described the witness as a well-respected member of the community, owner of a successful manufacturing company, and contributor to a number of charities. The low-status manipulation described the witness as a janitor at a local company, who had not finished high school, and whose family was partially supported by federal welfare checks. 
After reading one version of the testimony, subjects evaluated the witness's authoritativeness, character, sociability, and similarity to the subject on twenty-one seven-interval scales. The authoritativeness, character, and sociability scales were selected on the basis of Study 1. The similarity scales included three language similarity scales (Bradac, Desmond, \& Murdock, 1977) and two homophily scales (Wheeless, 1974).

Design and analysis. For all statistical tests alpha was set at .05 . Research question one was investigated by a 2 (high versus low status) $\times 2$ (high versus low intensifiers) $\times 2$ (high versus low hedges) $\times 2$ (high versus low hesitations) fixed effects analysis of variance. All were between-subjects factors. The measures were factor analyzed and factor scores were computed via a regression method and used as the dependent measures. Bartlett's test of sphericity indicated that multivariate analysis of variance was not warranted $\left(\chi^{2}=1.77, \mathrm{df}=6, p \square .94\right)$. Follow-up tests were conducted using Duncan's multiple-range test.

Research question two was investigated by a 2 (high versus low status) $\times 9$ (9 message conditions) fixed effects analysis of variance. Follow-up tests were conducted using Duncan's multiple-range test.

Results

Factor analysis of the dependent measures. As in Study 1 the dependent measures were factor analyzed. Principal components factor analysis with iterations, a varimax rotation, and a minimum eigenvalue extraction criterion of 1.0 produced a four-factor solution. Three of the four factors were the same as those in the first study: authoritativeness, character, and sociability. ${ }^{3}$ The fourth factor was a similarity dimension and was defined by the following items and their loadings: talks like me (.82), talks like my friends (.77), is like me (.74), is similar to me (.80), and thinks like me (.67).

The internal reliability for the authoritativeness, character, sociability, and similarity scales was $.88, .81, .72$, and .87 , respectively.

Manipulation check. A manipulation check determined whether the status manipulation was successful. Eighteen subjects from the same population used in the main study read either the low- or high-status description and evaluated the person on four scales, three of which were distractor items. The manipulation produced the expected difference, $t(16)=26.53, p<.0001$, low-status $M=1.89$, high-status $M=$ 6.78 . 
Authoritativeness. Analysis of variance revealed a significant main effect for hedges $\left(F[1,159]=5.95, p<.02\right.$, eta $\left.^{2}=.04\right)$ and a significant main effect for hesitations $\left(F[1,159]=9.31, p<.003\right.$, eta $\left.{ }^{2} \square .06\right)$. Low levels of hedges were perceived as more authoritative $(M=.22)$ than high levels of hedges $(M=-.13)$, and low levels of hesitations were perceived as more authoritative (Ma.28) than a high level of hesitations $(\mathrm{M}=-.16)$. No significant interactions were observed.

Sociability. The data indicated a significant triple interaction among speaker status, intensifiers, and hesitations $(F[1,159]$ - $3.95, p<.05$, eta $\left.^{2}=.02\right)$, which qualified a significant two-way interaction between speaker status and hesitations $\left(F[1,159]=7.28, \mathrm{p}<.01\right.$, eta $\left.^{2}=.03\right)$, and a significant hesitations main effect $\left(F[1,159] \square 4.08, p<.05\right.$, eta $\left.^{2}=.02\right)$. The means and standard deviations for the triple interaction are in Table 4. The low-status speaker who used a low level of intensifiers and hesitations was perceived as significantly more sociable than any other message condition. Also, a low-status speaker exhibiting low intensifiers and high hesitations was perceived as significantly less sociable than a low-status speaker exhibiting low intensifiers and low hesitations or a high-status speaker using high levels of intensifiers and hesitations.

The two-way interaction (see Table 4) indicated that a low-status speaker speaking with no hesitations was significantly more sociable than the other three message conditions. The other three messages did not differ significantly.

In addition a low level of hesitations was perceived as more sociable $(\mathrm{M}=.11)$ than a high level of hesitation $(\mathrm{M}=-.12)$.

Character. A speaker status by intensifiers interaction was found $\left(F[1,159]=3.76, p<.05\right.$, eta $\left.^{2} \square .02\right)$, which qualified a significant speaker status effect $\left(F[1,159]=4.46, p<.04\right.$, eta $\left.^{2}=.03\right)$ and a significant intensifiers effect $\left(F[1,159]=4.44, p<.04\right.$, eta $\left.^{2}=.03\right)$. Table 5 presents the means and standard deviations for this interaction. The high-status speaker who used a high level of intensifiers was perceived as having a much lower character than any other speaker status/message combination.

The speaker status main effect showed that a low-status speaker was perceived as having a more positive character $(M=.17)$ than a highstatus speaker $(M=-.12)$, while the intensifiers effect showed that low intensifiers were perceived as having a more positive character $(M=$ .17) than high intensifiers $(M=-.14)$. The one effect not qualified by the interactions, a hesitations main effect, revealed that a low level of 
TABLE 4

Sociability Factor Score Means and Standard Deviations for Speaker Status $X$ Intensifiers $X$ Hesitations

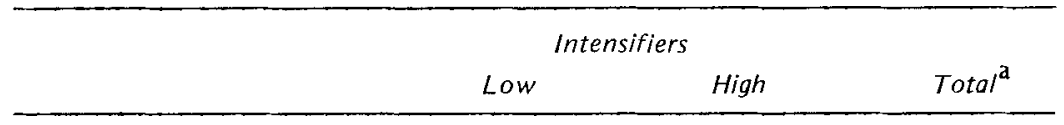

Low Speaker Status

Hesitations

Low

$$
\begin{aligned}
M & =.71^{a} \\
S D & =.62 \\
n & =21
\end{aligned}
$$

$M=.11^{b c}$

$M=.41^{\mathrm{a}}$

$\mathrm{SD}=1.09$

$\mathrm{SD}=.93$

$n=21$

$\mathrm{n}=42$

High

$\begin{aligned} M & =-.56^{c} \\ S D & =.96 \\ n & =23\end{aligned}$

$M=-.03^{b c}$

$M=-.30^{b}$

$\mathrm{SD}=.98$

$\mathrm{SD}=.99$

$\mathrm{n}=21$

$\mathrm{n}=44$

High Speaker Status

Hesitations

Low

$$
\begin{aligned}
M & =-.33^{b} \\
S D & =1.06 \\
n & =23
\end{aligned}
$$$$
M=.01^{b c}
$$$$
\mathrm{M}=-.17^{\mathrm{b}}
$$$$
\mathrm{SD}=1.03
$$$$
\mathrm{n}=21
$$$$
\mathrm{SD}=1.05
$$

High

$$
\begin{aligned}
M & =-.20^{b c} \\
S D & =1.03 \\
n & =24
\end{aligned}
$$$$
M=.10^{b}
$$$$
n=44
$$$$
\mathrm{SD}=.82
$$$$
\mathrm{n}=21
$$$$
\mathrm{M}=-.06^{\mathrm{b}}
$$

$$
n=21
$$$$
\mathrm{SD}=.94
$$$$
\mathrm{n}=45
$$

NOTE: Cell means with common superscripts do not differ significantly, $p<.05$. The higher the score, the higher the sociability.

a. Total means are computed by collapsing across intensifier conditions. They are the means for the speaker status $x$ hesitations interaction. Total means with common supersc rip ts do not differ significantly, $p<.05$.

hesitations was perceived as having higher character $(M=.27)$ than a high level of hesitations $(\mathrm{M}=-.12)$.

Similarity. Results of the analysis showed a significant main effect for hesitations $\left(F[1,159]=5.95, p<.02\right.$, eta $\left.{ }^{2}=.04\right)$, with low levels of hesitations perceived as more similar $(M=.20)$ than a high level of hesitations $(\mathrm{M}=-.18)$.

No other main or interactive effects were statistically significant (power, medium effect size, $=.89$ ).

Comparison with prototypically "powerless" message. Research question two asked whether the eight messages containing low and 


\section{TABLE 5}

Character Factor Score Means and Standard Deviations for Speaker Status. $X$ Intensifiers

\begin{tabular}{|c|c|c|}
\hline & \multicolumn{2}{|c|}{ Speaker Status } \\
\hline & Low & High \\
\hline \multicolumn{3}{|c|}{ Intensifiers } \\
\hline \multirow[t]{2}{*}{ Low } & $\mathrm{M}=.18^{\mathrm{a}}$ & $M=.16^{\mathrm{a}}$ \\
\hline & $\begin{aligned} S D & =.84 \\
n & =44\end{aligned}$ & $\begin{aligned} S D & =.86 \\
n & =47\end{aligned}$ \\
\hline \multirow[t]{3}{*}{ High } & $M=.15^{\mathrm{a}}$ & $M=-.44^{b}$ \\
\hline & $S D=.99$ & $S D=1.25$ \\
\hline & $n=42$ & $n=42$ \\
\hline
\end{tabular}

NOTE: Means with common superscripts do not differ significantly, $p<.05$. The higher the score, the higher the character.

high levels of hedges, hesitations, and intensifiers produced different evaluative consequences than a prototypical powerless message. The analysis of variance revealed a status main effect for the character $\left(F[1,178]=7.62, p<.006\right.$, eta $\left.^{2}=.04\right)$ and similarity scales $(F[1,178]=$ $5.84, p<.02$, eta $\left.{ }^{2} \square .03\right)$. The low-status speaker was evaluated as less similar and having a more negative character than the high-status speaker.

The analysis also produced a main effect for message condition on the authoritativeness $\left(F[8,178]=3.18, p<.002\right.$, eta ${ }^{2}$ a .12) and character scales $\left(F[8,178]=3.06, p<.003\right.$, eta $\left.{ }^{2} \square .12\right)$. The means and standard deviations are in Table 6 . The follow-up tests revealed that the high intensifiers/low hedges/low hesitations, the low intensifiers/low hedges/low hesitations, and the low intensifiers/high hedges/low hesitations messages were significantly more authoritative than the prototypically powerless message. Also, the high intensifiers/high hedges/low hesitations message was perceived as having significantly more character than the prototypically powerless message.

The interaction between status and message condition was not statistically significant (power, medium effect size, $=.66$ ).

\section{DISCUSSION}

This study indicated that judgments of authoritativeness were affected by hedges and hesitations individually, while judgments of 
TABLE 6

Authoritativeness and Character Factor Score Means for the Nine Message Groups in Study 2

\begin{tabular}{lcc}
\hline & Authoritativeness & Character \\
\hline $\begin{array}{l}\text { Low intensifiers/low } \\
\text { hedges/low hesitations }\end{array}$ & $.42^{\mathrm{a}}$ & $.38^{\mathrm{b}}$ \\
$\begin{array}{l}\text { Low intensifiers/low } \\
\text { hedges/high hesitations }\end{array}$ & $-.15^{\mathrm{b}}$ & $-.13^{\mathrm{b}}$ \\
$\begin{array}{l}\text { Low intensifiers/high } \\
\text { hedges/low hesitations }\end{array}$ & $.31^{\mathrm{a}}$ & $.42^{\mathrm{b}}$ \\
$\begin{array}{l}\text { Low intensifiers/high } \\
\text { hedges/high hesitations }\end{array}$ & $-.41^{\mathrm{b}}$ & $.04^{\mathrm{b}}$ \\
$\begin{array}{l}\text { High intensifiers/low } \\
\text { hedges/low hesitations }\end{array}$ & $.54^{\mathrm{a}}$ & $-.29^{\mathrm{b}}$ \\
$\begin{array}{l}\text { High intensifiers/low } \\
\text { hedges/high hesitations }\end{array}$ & $.09^{\mathrm{b}}$ & $-.35^{\mathrm{b}}$ \\
$\begin{array}{l}\text { High intensifiers/high } \\
\text { hedges/low hesitations }\end{array}$ & $-.21^{\mathrm{b}}$ & $.53^{\mathrm{a}}$ \\
$\begin{array}{l}\text { High intensifiers/high } \\
\text { hedges/high hesitations }\end{array}$ & $-.19^{\mathrm{b}}$ & $-.42^{\mathrm{b}}$ \\
\begin{tabular}{l} 
Powerless message \\
\hline
\end{tabular}
\end{tabular}

NOTE: Means with common superscripts do not differ significantly from the powerless message, $p<.05$. The higher the score, the higher the authoritativeness and character.

sociability and character were affected by interactions among speaker status, intensifiers, and hesitations, and speaker status and intensifiers, respectively. Low levels of hedges or hesitations were perceived as authoritative. The triple interaction among speaker status, intensifiers, and hesitations suggested that low-status speakers' perceived sociability is hurt by powerless speech style components and is enhanced by the absence of these components. The status by intensifiers interaction indicated that high-status speakers' perceived character may be hurt by the presence of a powerless speech component. Subjects apparently perceive a style low in hesitations to be similar to their own style.

The comparisons with a prototypically powerless message clearly indicated that messages high in only intensifiers, high in only hedges, or low in all three components are more powerful than the prototype. The 
finding for hedges is somewhat unusual because hedges are typically considered a powerless form.

\section{GENERAL DISCUSSION}

Across both studies only hedges and hesitations individually had consistent effects. Hedges lower evaluations of authoritativeness, while hesitations lower evaluations of authoritativeness and sociability. Interactions among components were not similar in both studies. Since the second study included a status factor, the two analyses are not completely comparable and the failure to find similar effects may be due to this. Pursued in a post hoc manner, the data from the second study were reanalyzed by collapsing across the status factor. No significant interactions emerged among the three power of speech style components. Only significant main effects for each variable were found. ${ }^{4}$ In general, therefore, individual effects of hesitations and hedges generalize across studies, while interactive effects do not.

These studies also examined whether messages exhibiting various combinations of the three components would differ from a prototypically powerless message in perceived authoritativeness. Both studies found that messages with low levels of intensifiers, hedges, and hesitations and a high level of intensifiers and low levels of hedges and hesitations were more powerful than the prototypically powerless message. Moreover, the perceived authoritativeness of the nine messages is relatively consistent across studies. A rank-order correlation between the message means in both studies was significant (Spearman rho $=.67$. $n=9, p=.025) .5$ Thus, although the lexical content of the two message sets is different, perceptions of each message type are relatively stable.

In short, both studies indicate that if speakers wish to be perceived as powerful, they should avoid using hesitations or hedges. If they wish to be perceived as sociable, they should avoid hesitations. Intensifiers are perceived as powerful, but only in the absence of hesitations or hedges.

Surprisingly, similar interactions among power of speech style components were not found in both studies. The hedges and hesitations interaction found in Study 1 was not found in Study 2, suggesting there may be some idiosyncratic characteristics of the messages which led to finding a significant interaction in Study 1. The significant rank-order correlation between message means in the studies would seem to mitigate against this.

The lack of generalizable interaction effects suggests other possible explanations. We may have strong stereotypes about hedges, hesita- 
tions, and intensifiers when they occur individually, but lack strong stereotypes about combinations of the three. For example, most interactions indicated that messages lacking any of the components are distinguishable from those containing one or more. Messages with one or more components, however, are relatively indistinguishable.

Another related explanation is that the three language components are associated with expectations about a speaker who exhibits them, and when speaker information is provided, these expectations are used and interactions between language components and speaker characteristics are found. This is consistent with Study 2 and one other study (Wright \& Hosman, 1983) in which speaker information was provided and it interacted with language variables. When speaker information is absent, subjects can only use the three components as the basis for evaluation, and as is suggested above, may not have strong or stable expectations about how they interact. This is consistent with Study 1 and another study (Hosman \& Wright, 1987) in which speaker information was not provided and interactions between language variables were found. Thus interactions involving language and speaker characteristics are more likely to be replicated than ones involving language variables alone.

The interaction effects in both studies are not additive, therefore limiting generalizability. That is, the addition of powerless style components to an already powerless message does not necessarily make it more powerless. This suggests that a threshold may exist such that the introduction of one powerless style component may produce the maximum negative consequences and the addition of others does not produce additional negative consequences. Determining when the threshold is reached may be of future interest. The component that occurs first or occurs with the greatest frequency earliest may set the evaluative level. For example, if hesitations are evaluated most negatively (Bradac \& Mulac, 1984) and occur first, the evaluations may be set at a lower level than if hedges occur first.

These findings have mixed implications for current thinking about powerful and powerless speech styles. Both support Bradac and Mulac's (1984) hierarchy of power in that hedges or hesitations are powerless and intensifiers are powerful. These results also offer some support for Berger and Bradac's (1982) claim that power of speech style is related to perceived lack of control or uncertainty in a situation. Language variables that indicate uncertainty, such as hesitations or hedges, are perceived as relatively powerless. 
On the other hand, these results also suggest that language variables may signal two types of uncertainty that are related differently to attributions of authoritativeness and sociability. One type of uncertainty is lack of control in a context. Speakers who are uncertain may hesitate or hedge, which, in turn, causes them to be perceived as nonauthoritative. The other type of uncertainty is due either to understanding that the world is probabilistic, requiring qualification of comments, or to planning of one's comments. This could be labeled "rhetorical uncertainty" and would be a more positive form attributionally than the other type. This type of uncertainty would be associated with sociability and character judgments rather than authoritativeness judgments. Speakers who are too sure of their ideas, do not hedge, and do intensify may be perceived as dogmatic, unsociable, and dishonest.

These results also modify existing thought on other issues. First, intensifiers do not consistently affect perceptions of powerfulness (Bradac \& Mulac, 1984) or powerlessness (O'Barr, 1982), particularly when in the presence of other linguistic variables. Two other studies (Bradac, Courtright, \& Bowers, 1980; Wright \& Hosman, 1983) have similarly found that in the context of other language variables intensifiers do not produce significant evaluative consequences. ${ }^{6}$ Inclusion of intensifiers in powerful or powerless speech style messages may produce spurious results. Minimally, this particular component's relationship to perceptions of authoritativeness needs further exploration.

Second, the powerless speech style construct is not parsimonious. In both studies the perceived authoritativeness of the powerless message was not significantly different from that of other messages containing many fewer components, indicating that the powerless message contains elements that either do not contribute to perceptions of powerlessness, such as intensifiers, or are inconsistent with the concept of powerlessness. Future research needs to focus on the components rather than the molar construct of a powerless speech style.

Third, the relative absence of any effects involving the similarity measure in Study 2 suggests that similarity may not be directly involved in the uncertainty reduction process as postulated by Berger and Bradac. This conclusion must be accepted cautiously because it needs to be replicated, plus the study examined only the simplest of four possible models. Similarity may be related to uncertainty reduction in more complex ways. 
The results of the second study also suggest that speaker status may moderate the effects of the components, although only for judgments of character and sociability. Specifically, a high-status speaker using intensifiers was perceived to have low character, while a low-status speaker using no intensifiers or hesitations was perceived as very sociable. Receivers may have expectations about how high- and lowstatus speakers talk, and when these expectations are violated, in either a positive or negative way, their evaluations are affected.

Also worthy of note is the failure to find any significant respondent gender differences in Study 1. Although some studies have found gender effects (Bradac \& Mulac, 1984, Study 2; Erickson et al., 1978), a mounting number of studies have not (Bradac \& Mulac, 1984, Study 1; Bradac et al., 1981; Lind \& O'Barr, 1979; Warfel, 1984; Wright \& Hosman, 1983). At this point, the relationship between gender of audience and powerful/powerless speech styles is still unclear, although the weight of the evidence suggests that the relationship is negligible. Given the status effects observed in Study 2, it may be important to pursue this latter variable in future research.

One potential limitation of these studies must be considered. Can the results be generalized to oral messages? The answer is yes. Research by O'Barr (1982) comparing the oral and written mode found no significant differences in the evaluative consequences of powerful and powerless speech styles. Furthermore, these results are consistent with other research on the evaluative consequences of hedges (Newcombe \& Arnkoff, 1979) and hesitations (Miller \& Hewgill, 1964) in the oral mode. Finally, although one might think that a component such as hesitations would be more noticeable in a written mode than an oral mode, the variance accounted for in both studies by hesitations was about the same as or lower than that accounted for by hedges or intensifiers. No one component would seem to be more salient in a written mode.

While these results appear to be robust, the evaluative consequences might change somewhat with the addition of paralinguistic or other nonverbal cues. For example, one could stress or not stress intensifiers paralinguistically. A stressed intensifier might connote powerfulness, while an unstressed intensifier might operate as a filler or intensifier.

In summary, this article looked at the separate and combined impact of hedges, hesitations, and intensifiers on evaluations of a speaker's authoritativeness, sociability, character, and similarity. Two studies' results showed that main effects for hedges and hesitations were similar 
in both studies, while interactive effects were not. Additionally, these studies examined whether messages exhibiting different combinations of hedges, hesitations, and intensifiers produced different evaluations than a prototypically powerless message. The results indicated that a powerless speech style is not a parsimonious construct. Additional research should continue to focus on the potential interactions between the components.

\section{NOTES}

1. The actual kernel message was approximately 315 words in length, and the other eight messages ranged from approximately 325 to 375 words in length.

2. One might question why comparisons were not made between the eight messages containing various combinations of hedges, hesitations, and intensifiers. This is the same as conducting follow-up tests on a three-way interaction, which would be inappropriate here because the interaction was not significant.

3. The authoritativeness factor was defined by the following items and their loadings: authoritative (.72), dominant (.74), strong (.72), aggressive (.79), confident (.67), and socioeconomic status (.59). The character factor was defined by the following items and their loadings: honest (.82), trustworthy (.78), and competent (.64). The sociability dimension included the following items and their loadings: pleasant (.74), likeable (.58), good-natured (.79), and sociable (.60).

4. On the authoritativeness scale there was a significant main effect for hesitations $\left(F[1,167]=9.52, p<.002\right.$, eta $\left.^{2} \square .05\right)$ and a significant main effect for hr dges $(F[1,167] \square$ $6.22, p<.01$, eta $\left.{ }^{2} .04\right)$. On the character scale there was a significant hesitations main effect $\left(F[1,167]=10.35, p<.002\right.$, eta $\left.{ }^{2} \square .06\right)$ and a significant intensifiers effect $(F[1,167]=$ $4.38, p<.04$, eta ${ }^{2} \square .03$ ). A significant hesitations main effect was found on the similarity scale $\left(F[1,167]=5.78, p<.02\right.$, eta $\left.^{2}=.03\right)$.

5. The rank-order correlation for the sociability measures was not significant (Spearman rho $=.27, n=9, p=.24$ ), nor was the correlation for the character measures (Spearman rho $=-.05, \mathrm{n}=9, p$ 口 .45).

6. One might argue that intensifiers did not produce significant effects because they were pitted against two powerless components. This was not judged to be a problem because the power analysis indicated a reasonably good likelihood of finding an intensifiers' effect. Further, prior research (Wright \& Hosman, 1983) pitting intensifiers against only one other component did not find any significant evaluative consequences due to intensifiers. It does not seem reasonable to argue, therefore, that it was an unfair test of the intensifiers effect.

\section{REFERENCES}

Berger, C. R., \& Bradac, J. J. (1982). Language and social knowledge: Uncertainty in interpersonal relationships. London: Edward Arnold.

Bradac, J. J., Bowers, J. W., \& Courtright, J. A. (1979). Three language variables in communication research: Intensity, immediacy, and diversity. Human Communication Research, 5, 257-269. 
Bradac, J. J., Courtright, J. A., \& Bowers, J. W. (1980). Effects of intensity, immediacy and diversity upon receiver attitudes toward a belief-discrepant message and its source. In H. Giles, W. P. Robinson, \& P. Smith (Eds.), Language: Social psychological perspectives (pp. 217-221). Oxford: Pergamon.

Bradac, J. J., Courtright, J. A., Schmidt, G., \& Davies, R. A. (1976). The effects of perceived status and linguistic diversity upon judgments of speaker attributes and message effectiveness. Journal of Psychology, 93, 213-220.

Bradac, J. J., Desmond, R. J., \& Murdock, J. I. (1977). Diversity and density: Lexically determined evaluative and informational consequences of linguistic complexity. Communication Monographs, 44, 272-283.

Bradac, J. J., Hemphill, M. R., \& Tardy, C. H. (1981). Language style on trial: Effects of "powerful" and "powerless" speech upon judgments of victims and villains. Western Journal of Speech Communication, 45, 327-341.

Bradac, J. J., Konsky, C. W., \& Davies, R. A. (1976). Two studies of the effects of linguistic diversity upon judgments of communicator attributes and message effectiveness. Communication Monographs, 43, 1-17.

Bradac, J. J., \& Mulac, A. (1984). A molecular view of powerful and powerless speech styles: Attributional consequences of specific language features and communicator intentions. Communication Monographs, 51, 307-319.

Bradac, J. J., Schneider, M. J., Hemphill, M. R., \& Tardy, C.H. (1980). Consequences of language intensity and compliance-gaining strategies in an initial heterosexual encounter. In H. Giles, W. P. Robinson, \& P. Smith (Eds.), Language: Social psychological perspectives (pp. 71-75). Oxford: Pergamon.

Cronbach, L. J. (1951). Coefficient alpha and the internal structure of tests. Psychometrika, 16, 297-334.

Erickson, B., Lind, E. A., Johnson, B. C., \& O’Barr, W. M. (1978). Speech style and impression formation in a court setting: The effects of "powerful" and "powerless" speech. Journal of Experimental Social Psychology, 14, 266-279.

Goss, B., \& Williams, M. L. (1973). The effects of equivocation on perceived source credibility. Central States Speech Journal, 24, 162-167.

Hosman, L. A., \& Wright, J. W., II. (1987) The effects of hedges and hesitations on impression formation in a simulated courtroom context. Western Journal of Speech Communication, 51, 173-188.

Jackson, S., \& Jacobs, S. (1983). Generalizing about messages: Suggestions for design and analysis of experiments. Human Communication Research, 9, 169-181.

Johnson, C., \& Vinson, L. (1987). “Damned if you do, damned if you don't?" Status, powerful speech, and evaluations of female witnesses. Women's Studies in Communication, 10, 37-44.

Lind, E. A., \& O'Barr, W. M. (1979). The social significance of speech in the courtroom. In H. Giles \& R. St. Clair (Eds.), Language and social psychology (pp. 66-87). Baltimore: University Park Press.

Maclay, G. F., \& Osgood, C. E. (1959). Hesitation phenomena in spontaneous English speech. Word, 15, 19-44.

McCroskey, J. C., \& Mehrley, R. S. (1969). The effects of disorganization and nonfluency on attitude change and source credibility. Speech Monographs, 36, 13-21.

McCroskey, J. C., \& Young, T. J. (1981). Ethos and credibility: Its measurement after three decades. Central States Speech Journal, 32, 24-34. 
McEwen, W. J., \& Greenberg, B. S. (1970). Effects of message intensity on receiver evaluations of source, message, and topic. Journal of Communication, 20, 340-350.

Miller, G. R., \& Hewgill, M. A. (1964). The effects of variations in nonfluency on audience ratings of source credibility. Quarterly Journal of Speech Communication, 50, 36-44.

Newcombe, N., \& Arnkoff, D. B. (1979). Effects of speech style and sex of speaker on person perception. Journal of Personality and Social Psychology, 37, 1293-1303.

O'Barr, W. M. (1982). Linguistic evidence: Language, power, and strategy in the courtroom. New York: Academic Press.

Sereno, K. K., \& Hawkins, G. J. (1967). The effects of variations in speakers' nonfluency upon audience ratings of attitude toward the speech topic and speaker credibility. Speech Monographs, 34, 58-64.

Warfel, K. A. (1984). Gender schemas and perceptions of speech style. Communication Monographs, 51, 253-267.

Wheeless, L. R. (1974). The effects of attitude, credibility, and homophily on selective exposure to information. Speech Monographs, 41, 329-338.

Wright, J. W., II, \& Hosman, L. A. (1983). Language style and sex bias in the courtroom: The effects of male and female use of hedges and intensifiers on impression formation. Southern Speech Communication Journal, 48, 137-152. 